\title{
PENGARUH IGNITION TIMING DENGAN BAHAN BAKAR LPG TERHADAP UNJUK KERJA MESIN BENSIN EMPAT LANGKAH SATU SILINDER
}

\author{
I Made Mara, Made Wirawan, Towilan Ma'bud \\ Jurusan Teknik Mesin Fakultas Teknik Universitas Mataram \\ Jln. Majapahit No.62 Mataram Nusa Tenggara Barat Kode Pos: 83125 \\ Telp. (0370) 636087; 636126; ext 128 Fax (0370) 636087
}

\begin{abstract}
Shortage of petroleum in Indonesia is a problem that triggers people to look for alternative fuels derived fuel. One of them is the use of LPG fuel as motorcycle fuel. And to improve the performance and efficiency of the use of LPG fuel in vehicles is one of them by varying the ignition timing.

The aim of this study to explore the effect of ignition timing on the torque, power and specific fuel consumption effective (SFCE) with LPG fuel using converter kit on petrol engine four stroke single cylinder Honda Astrea Prima $100 \mathrm{cc}$. In this study, the ignition timing is varied at $15^{\circ}, 17^{\circ}, 19^{\circ}$ and $21^{\circ}$ before TDC and to set engine rotation at $1500 \mathrm{rpm}, 2500 \mathrm{rpm}, 3500 \mathrm{rpm}$ and $4500 \mathrm{rpm}$.

The results of the experiments conducted in this study show a better performance of the engine when the ignition timing advanced earlier. Highest torque at $17^{\circ}$ before TDC is 0,507 $\mathrm{kgf.m}$ at $4500 \mathrm{rpm}$, the highest effective power at $17^{\circ}$ before TDC is 3,183 PS at $4500 \mathrm{rpm}$, and the lowest SFCE at $17^{\circ}$ before TDC is $0,084 \mathrm{~kg} / \mathrm{jam}$.PS at $4500 \mathrm{rpm}$.
\end{abstract}

Keywords: ignition timing, $L P G$, engine rotation, performance.

\section{PENDAHULUAN}

Untuk mengatasi keterbatasan minyak bumi di Indonesia perlu dilakukan pencarian dan penggunaan sebuah alternatif dari bahan bakar minyak (BBM). Hal ini yang mendorong masyarakat untuk berusaha mencari bahan bakar alternatif sebagai pengganti bahan bakar minyak. Salah satu jenis bahan bakar alternatif yang saat ini dikembangkan dan memungkinkan untuk mengurangi ketergantungan akan BBM terutama untuk kendaraan bermotor adalah bahan bakar gas (BBG).

Bahan bakar gas yang paling banyak beredar di Indonesia adalah Liquefied Petroleum Gas (LPG) utamanya terdiri dari gas propana, propilena, butana dan butilena pada berbagai konsentrasi kandungan menurut keadaannya atau asalnya. Komponen penyusun LPG berada pada fasa gas pada temperatur dan tekanan normal tapi dengan mudah dapat dicairkan untuk penyimpanan dengan menaikkan tekanan sampai sekitar 8 atm atau dengan menurunkan temperatur.

Untuk meningkatkan performa mesin pada motor pembakaran dalam dengan bahan bakar LPG dapat dilakukan pada saat pembakaran yakni dengan memvariasikan waktu pengapian dan mencari waktu yang menghasilkan performa yang maksimal

Berdasarkan uraian diatas maka dapat dirumuskan bagaimana pengaruh dari pemasukan bahan bakar gas LPG yang diinjeksikan ke dalam main jet karburator dengan memvariasikan waktu pengapian Honda Astrea Prima 100cc terhadap unjuk kerja mesin.

Melihat perlu adanya batasan masalah agar pokok pembahasan tidak keluar dari konteks, maka dibuatlah batasan-batasan antara lain:

1. Pengujian dilakukan pada motor bensin 4 langkah satu silinder (Honda Astrea Prima).

2. Bahan bakar gas yang digunakan adalah LPG $3 \mathrm{~kg}$ produksi pertamina.

3. Tidak membahas emisi gas buang.

4. Pengujian dilakukan untuk mengetahui peningkatan torsi, daya, dan SFCe.

Tujuan dari penelitian ini adalah untuk mencari pengaruh waktu pengapian terhadap torsi, daya efektif, dan specific fuel consumption effective (SFCe) dengan bahan bakar LPG menggunakan konversi kit pada mesin bensin empat langkah satu silinder.

Manfaat yang diharapkan dari penelitian ini adalah dapat memberikan gambaran dan pengetahuan mengenai teknologi otomotif, sehingga setelah didapat waktu pengapian yang menghasilkan performa yang maksimal maka dapat diaplikasikan pada motor bensin empat langkah satu silinder berbahan bakar LPG. 


\section{LANDASAN TEORI}

Penelitian yang dilakukan oleh [1] mengenai pengaruh variasi sudut penyalaan terhadap daya engine Toyota K-4 dengan bahan bakar gas, dengan variasi waktu pengapian $5^{\circ}, 10^{\circ}, 15^{\circ}$ sebelum TMA didapatkan hasil dengan daya yang meningkat sebesar $12,96 \%$ pada perubahan waktu pengapian $10^{\circ}$ sebelum TMA.

Motor bakar merupakan salah satu jenis dari mesin kalor, yakni mesin yang merubah energi panas untuk melakukan kerja mekanik. Energi diperoleh dari proses pembakaran, proses pembakaran juga mengubah energi tersebut yang terjadi didalam dan diluar mesin kalor. Mesin merupakan alat yang mengubah sumber tenaga panas, listrik, air, angin, atau sumber tenaga lainya menjadi tenaga mekanik. [2]

Ada dua macam mesin kalor jika dilihat dari cara kerjanya, antara lain:

1. Mesin pembakaran dalam atau internal combustion engine (ICE), yaitu mesin yang proses pembakarannya di dalam mesin itu sendiri dan langsung dipakai untuk melakukan kerja mekanis. Contohnya mesin bensin, mesin diesel, dan lain-lain.

2. Mesin pembakaran luar atau external combustion engine (ECE), yaitu mesin yang proses pembakarannya terjadi di luar mesin itu sendiri. Contohnya turbin uap, turbin gas, dan lain-lain.

Pada awalnya campuran udara dan bensin dihisap ke dalam silinder yang kemudian dikompresikan oleh torak yang bergerak naik. Jika campuran udara dan bensin terbakar seiring dengan adanya letikan bunga api dari busi, maka akan menghasilkan tekanan gas pembakaran yang besar di dalam silinder. Dari gerakan torak yang turun naik yang kemudian dirubah menjadi gerak putar pada poros engkol melalui batang torak [3].

1. Langkah hisap

Pada langkah ini, melalui katup hisap campuran udara dan bensin masuk ke dalam silinder. Katup hisap terbuka sedangkan katup buang tertutup. Saat torak berada di bawah katup hisap akan tertutup.

2. Langkah kompresi

Pada langkah ini, campuran udara dan bensin dikompresikan. Katup hisap dan katup buang tertutup. Saat torak mulai naik dari titik mati bawah (TMB) ke titik mati atas (TMA) campuran yang terhisap dikompresikan, yang menyebabkan tekanan dan temperaturnya menjadi naik.
Beberapa saat sebelum torak mencapai TMA busi meletikan bunga api dari busi.

3. Langkah usaha

Pada langkah ini, kedua katup masih dalam keadaan tertutup. Gas terbakar dengan tekanan pembakaran yang tinggi mendorong torak ke bawah yang selanjutnya diteruskan oleh poros engkol sehingga menghasilkan tenaga mesin.

4. Langkah buang

Pada langkah ini, katup buang terbuka, gas hasil pembakaran dikeluarkan melalui katup buang. Torak bergerak dari TMB ke TMA, mendorong gas bekas keluar silinder. Ketika torak mencapai TMA, maka torak mulai bergerak lagi untuk persiapan langkah berikutnya, yaitu langkah hisap.

Waktu pengapian (ignition timing) merupakan waktu dimana busi mulai memantikkan api di dalam ruang bakar, pembakaran campuran udara dan bahan bakar mencapai sempurna memerlukan waktu kurang dari 2 milidetik. Bunga api harus dipantikkan lebih awal.

Sistem pengapian pada motor bensin berfungsi mengatur proses pembakaran campuran bensin dan udara di dalam silinder sesuai waktu yang sudah ditentukan. Saat penyalaan yang tepat sangat mempengaruhi proses pembakaran sempurna. Sistem pengapian terdiri dari berbagai komponen, yang bekerja bersamasama dalam waktu yang sangat cepat dan singkat. Bila saat pengapian dimajukan terlalu jauh, maka tekanan pembakaran maksimum akan tercapai sebelum $10^{\circ}$ sesudah TMA. Karena tekanan di dalam silinder akan menjadi lebih tinggi daripada pembakaran dengan waktu yang tepat, pembakaran campuran udara bahan bakar yang spontan akan terjadi dan akhirnya akan terjadi knocking atau detonasi. [4].

Knocking adalah ledakan yang menghasilkan gelombang kejutan berupa suara ketukan dikakarenakan naiknya tekanan yang besar dan kuat pada pada akhir pembakaran. Saat pengapian terlalu maju juga mengakibatkan suhu mesin menjadi terlalu tinggi. Sedangkan bila saat pengapian dimundurkan terlalu jauh, maka tekanan pembakaran maksimum terjadi setelah $10^{\circ}$ setelah TMA. Bila dibandingkan dengan pengapian yang waktunya tepat, maka pembakaran dapat menghasilkan tekanan pembakaran yang optimal. [4].

Selain itu, waktu pengapian harus disesuaikan dengan angka oktan dari bahan bakar yang digunakan. Berubahnya angka 
oktan dari bahan bakar harus diikuti dengan penyetelan waktu pengapian. Rekomendasi yang diberikan oleh pabrik kendaraan biasanya mensyaratkan penggunaan bensin tanpa timbal untuk mesin dengan sistem bahan bakar injeksi. Hal ini menyebabkan waktu pengapian bisa tidak tepat karena titik bakar dari bensin tidak sesuai dengan ketentuan. Oleh karena itu, waktu pengapian yang tepat sangat diperlukan untuk mengoptimalkan performa mesin. [5]. Liquefied petroleum gas (LPG) merupakan campuran hidrokarbon yang terdiri dari propana $\left(\mathrm{C}_{3} \mathrm{H}_{8}\right)$ dan butana $\left(\mathrm{C}_{4} \mathrm{H}_{10}\right)$ serta beberapa kandungan hidrokarbon lain pada berbagai konsentrasi kandungan menurut keadaan maupun asalnya. Komponen penyusun LPG berada pada fasa gas pada temperatur dan tekanan normal, namun dengan meninggikan tekanan sampai sekitar 8 atm dan menurunkan temperatur maka gas akan berubah fasa menjadi fasa cair.

Adapun untuk kelebihan dan

kekurangan bahan bakar LPG antara lain:

1. LPG telah berada pada fasa gas, sehingga lebih mudah dalam pencampuran bahan bakar dan udara

2. Emisi gas buang yang dihasilkan dari pembakaran lebih bersih.

3. LPG memiliki kandungan energi lebih rendah per volume dibandingkan bahan bakar minyak

\section{Fuel Consumption (FC)}

Pengukuran dalam pemakaian bahan bakar gas LPG biasanya diukur dalam satuan massa penggunaan bahan bakar per satuan waktu, yakni dalam satuan kilogram per jam.

Besarnya konsumsi bahan bakar dapat dihitung dengan persamaan:

$$
F C=\frac{b}{t}(\mathrm{~kg} / \mathrm{jam})
$$

dengan :

$$
\begin{aligned}
& \mathrm{b}: \text { massa pemakaian bahan bakar, }(\mathrm{kg}) \\
& \mathrm{t}: \text { waktu yang digunakan untuk } \\
& \text { mengkonsumsi bahan bakar,(detik) }
\end{aligned}
$$

\section{Torsi (T)}

Dalam pengukuran besarnya torsi perlu adanya peralatan yang biasa disebut torsi meter. Pada prinsipnya alat ukur torsi ini memanfaatkan putaran dari poros engkol yang kemudian diteruskan ke transmisi melalui kopling. Poros keluaran dari transmisi digabung langsung dengan sproket kemudian dengan penghubung rantai menggerakkan sproket belakang yang berhubungan langsung dengan tromol roda belakang. Perhitungan nilai torsi dengan cara melihat besarnya gaya pengereman (kg) pada neraca pegas kemudian dikalikan dengan panjang lengan ( $\mathrm{mm})$ yang dirumuskan sebagai berikut [6]:

$$
T=L \times F \ldots \ldots(k g . m)
$$

dengan :

$$
\begin{aligned}
& \mathrm{L}: \text { Panjang lengan, }(\mathrm{m}) \\
& \mathrm{F}: \text { Gaya tangensial stator, }(\mathrm{kg}) \\
& \mathrm{T} \text { : Torsi }(\mathrm{kg} \cdot \mathrm{m})
\end{aligned}
$$

\section{Daya Efektif (NE)}

Besarnya daya efektif ( $\mathrm{Ne}$ ) akan tergantung dari besarnya torsi dan putaran yang terjadi. Hal ini dapat dilihat dari persamaan berikut [7]:

$$
N e=\frac{T \times n}{716,2}(P S)
$$

dengan :

Ne: Daya efektif (PS)

$\mathrm{T}$ : Torsi (kg.m)

$\mathrm{n}$ : Putaran mesin (rpm)

\section{Specific Fuel Consumption Effective (SFCE)}

Konsumsi bahan bakar efektif atau specific fuel consumption effective (SFCe) ditentukan dengan persamaan [7]:

$$
S F C e=\frac{F C}{N e} \ldots . .(k g / j a m . P S)
$$

dengan :

$$
\begin{aligned}
& \text { FC : Penggunaan bahan bakar pada } \\
& \text { kondisi tertentu, (kg / jam) } \\
& \mathrm{Ne} \mathrm{:} \mathrm{Daya} \mathrm{efektif,} \mathrm{(PS)}
\end{aligned}
$$

\section{METODE PENELITIAN}

Dalam penelitian ini ada dua macam variabel yang digunakan, yaitu :

1. Variabel Terikat

Untuk variabel terikat dalam pengujian ini adalah :

a. Torsi

b. Daya efektif

c. Specific fuel consumption effective (SFCe).

2. Variabel bebas

Adapun variabel bebas dalam penelitian ini, yaitu :
a. Variasi waktu pengapian $15^{\circ}$ (standar), $17^{\circ}, 19^{\circ}$ dan $21^{\circ}$ sebelum TMA. 
b. Putaran mesin yang digunakan adalah 1500, 2500, 3500 dan 4500 $( \pm 100 \mathrm{rpm})$.

\section{Alat Dan Bahan}

Pada penelitian ini menggunakan kendaraan uji motor bensin Honda Astrea Prima 100 cc tahun 1990 dengan Tipe Mesin $\mathrm{OHC}, 4$ langkah, pendingin udara dengan volume langkah $97,1 \mathrm{~cm}^{3}$.

Untuk konversi kit yang digunakan dengan rangkaian modifikasi menggunakan regulator LPG, flow control, selang gas dan pipa tembaga.

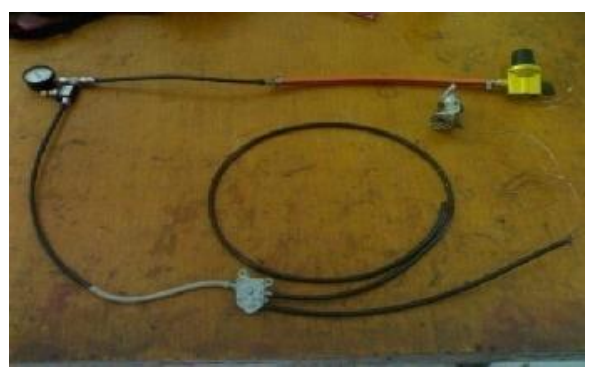

Gambar 1. Konversi kit

\section{Prosedur Penelitian}

Persiapan dilakukan terlebih dahulu baik itu alat maupun bahan yang akan digunakan selama pengujian, kemudian pada saat pengujian lebih dulu memanaskan mesin sampai temperature kerjanya selama 2-3 menit.

Pengujian dilakukan menggunakan bahan bakar bensin sebagai pembanding dengan pemasangan flywhee/ magnet waktu pengapian $15^{\circ}$ sebelum TMA dan dilanjutkan menggunakan bahan bakar gas LPG dengan pemasangan flywheel magnet waktu pengapian $15^{\circ}, 17^{\circ}, 19^{\circ}$ dan $21^{\circ}$ sebelum TMA dengan variasi putaran mesin 1500, 2500, 3500 dan 4500 rpm, kemudian mencatat besarnya gaya pengereman dan fuel consumption. Setelah semua tahapan pengujian dilakukan maka tahap selanjutnya yakni perhitungan dan analisa data.

\section{HASIL DAN PEMBAHASAN}

\begin{tabular}{|c|c|c|c|c|c|}
\hline \multirow{2}{*}{$\begin{array}{c}\text { Putaran } \\
\mathrm{rpm}\end{array}$} & \multicolumn{4}{|c|}{ Waktu pengapian (sebelum TMA) } & \multirow{2}{*}{ Bensin } \\
\hline & $15^{\circ}$ & $17^{\circ}$ & $19^{\circ}$ & $21^{\circ}$ & \\
\hline 1500 & 0.174 & 0.149 & 0.159 & 0,099 & 0,211 \\
\hline 2500 & 0,258 & 0,221 & 0,252 & 0,127 & 0,314 \\
\hline 3500 & 0,336 & 0,345 & 0,305 & 0,199 & 0,389 \\
\hline 4500 & 0.420 & 0.507 & 0.482 & 0.311 & 0.569 \\
\hline
\end{tabular}

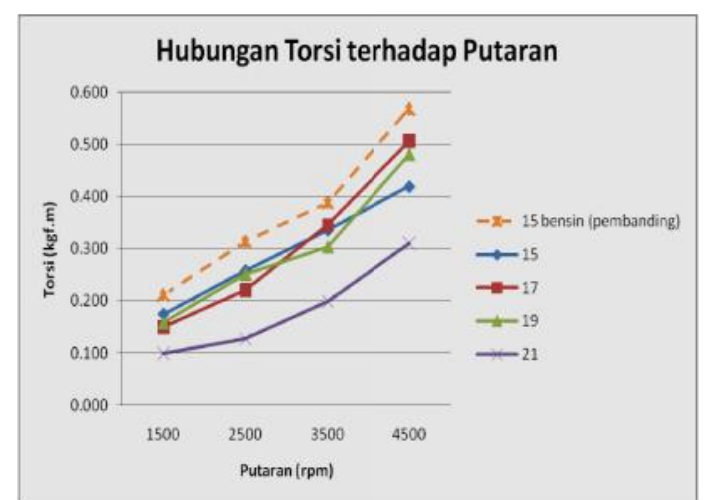

Gambar 2. Grafik hubungan torsi terhadap putaran.

Dari grafik torsi terhadap putaran di atas terlihat bahwa torsi yang dihasilkan oleh mesin meningkat berbanding lurus dengan meningkatnya putaran mesin. Torsi yang dihasilkan melalui pembakaran bahan bakar semakin meningkat, dikarenakan jumlah bahan bakar yang masuk ke dalam ruang bakar bertambah seiring dengan meningkatnya putaran mesin.

Secara keseluruhan dengan bahan bakar LPG torsi tertinggi yang dihasilkan pada waktu pengapian $17^{\circ}$ sebelum TMA sebesar $0,507 \mathrm{kgf} . \mathrm{m}$ dan torsi terendah dihasilkan pada waktu pengapian $21^{\circ}$ sebelum TMA sebesar 0,099 kgf.m. Pada putaran $4500 \mathrm{rpm}$ torsi tertinggi dihasilkan pada waktu pengapian $17^{\circ}$ sebelum TMA sebesar 0,507 kgf.m dan terendah pada waktu pengapian $21^{\circ}$ sebelum TMA sebesar 0,311 kgf.m sedangkan dengan penggunaan bahan bakar bensin torsi yang dihasilkan sebesar 0,569 kgf.m. Perbedaan yang signifikan terlihat pada waktu pengapian $21^{\circ}$ sebelum TMA, Hal ini dikarenakan waktu pengapian yang terlalu maju menyebabkan terjadinya pembakaran di luar waktu yang seharusnya dan terjadi penyalaan bahan bakar sendiri (autoignition) sehingga campuran bahan bakar dan udara tidak terbakar pada saat pengapian oleh busi yang menimbulkan detonasi.

Tabel 2. Data Daya efektif (PS)

\begin{tabular}{|c|c|c|c|c|c|}
\hline \multirow{2}{*}{$\begin{array}{c}\text { Putaran } \\
\text { rpm }\end{array}$} & \multicolumn{4}{|c|}{ Waktu pengapian (sebelum TMA) } & \multirow{2}{*}{ Bensin } \\
\cline { 2 - 5 } & $15^{\circ}$ & $17^{\circ}$ & $19^{\circ}$ & $21^{\circ}$ & \\
\hline 1500 & 0,365 & 0,312 & 0,332 & 0,208 & 0,443 \\
\hline 2500 & 0,900 & 0,770 & 0,879 & 0,445 & 1,096 \\
\hline 3500 & 1,640 & 1,686 & 1,488 & 0,972 & 1,899 \\
\hline 4500 & 2,636 & 3,183 & 3,027 & 1,953 & 3,574 \\
\hline
\end{tabular}




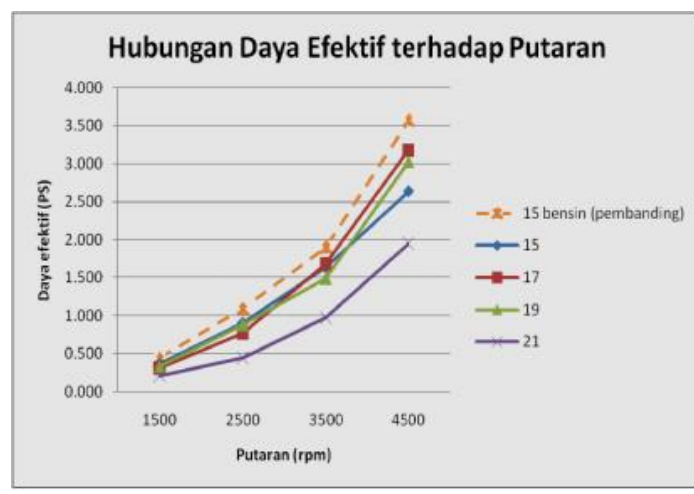

Gambar 2. Grafik hubungan daya efektif terhadap putaran.

Dari grafik di atas terlihat bahwa daya efektif yang dihasilkan meningkat seiring dengan meningkatnya putaran mesin.

Dengan penggunaan bahan bakar LPG daya efektif tertinggi yang dihasilkan pada waktu pengapian $17^{\circ}$ sebelum TMA sebesar 3,183 PS dan daya efektif terendah dihasilkan pada waktu pengapian $21^{\circ}$ sebelum TMA sebesar 0,208 PS. Pada putaran $4500 \mathrm{rpm}$ daya efektif tertinggi dihasilkan pada waktu pengapian $17^{\circ}$ sebelum TMA sebesar 3,183 PS dan terendah pada waktu pengapian $21^{\circ}$ sebelum TMA sebesar 1,953 PS sedangkan dengan penggunaan bahan bakar bensin daya efektif yang dihasilkan sebesar 3,574 PS.

Seperti yang terjadi pada torsi, daya efektif pada waktu pengapian $17^{\circ}$ sebelum TMA memiliki nilai yang paling besar dikarenakan tekanan hasil pembakaran dalam ruang bakar yang optimal, sehingga tekanan hasil pembakaran tersebut menghasilkan daya yang diteruskan oleh torak yang kemudian memutar flywheel sebagai sebuah daya yang akan diteruskan ke roda. Sedangkan pada waktu pengapian $21^{\circ}$ sebelum TMA daya yang dihasilkan cenderung lebih rendah disebabkan oleh puncak tekanan hasil pembakaran yang terlalu awal sehingga tekanan tersebut menghambat gerak piston saat kompresi yang menyebabkan daya yang akan diteruskan sebagai langkah usaha menjadi kecil. Hal tersebut menyebabkan daya yang diteruskan ke roda pun menjadi rendah.

Tabel 3. Data Fuel Consumption (kg/jam)

\begin{tabular}{|c|c|c|c|c|c|}
\hline \multirow{2}{*}{$\begin{array}{c}\text { Putaran } \\
\text { rpm }\end{array}$} & \multicolumn{4}{|c|}{ Waktu pengapian (sebelum TMA) } & \multirow{2}{*}{ Bensin } \\
\cline { 2 - 5 } & $15^{\circ}$ & $17^{\circ}$ & $19^{\circ}$ & $21^{\circ}$ & \\
\hline 1500 & 0,133 & 0,100 & 0,133 & 0,133 & 0,129 \\
\hline 2500 & 0,200 & 0,133 & 0,200 & 0,200 & 0,168 \\
\hline 3500 & 0,233 & 0,233 & 0,267 & 0,333 & 0,253 \\
\hline 4500 & 0,333 & 0,267 & 0,333 & 0,400 & 0,297 \\
\hline
\end{tabular}

Tabel 4. Data SFCe (kg/jam.PS)

\begin{tabular}{|c|c|c|c|c|c|}
\hline \multirow{2}{*}{$\begin{array}{c}\text { Putaran } \\
\text { rpm }\end{array}$} & \multicolumn{4}{|c|}{ Waktu pengapian (sebelum TMA) } & \multirow{2}{*}{ Bensin } \\
\cline { 2 - 5 } & $15^{\circ}$ & $17^{\circ}$ & $19^{\circ}$ & $21^{\circ}$ & \\
\hline 1500 & 0,366 & 0,320 & 0,402 & 0,640 & 0,291 \\
\hline 2500 & 0,222 & 0,173 & 0,228 & 0,450 & 0,154 \\
\hline 3500 & 0,142 & 0,138 & 0,179 & 0,343 & 0,133 \\
\hline 4500 & 0,126 & 0,084 & 0,110 & 0,205 & 0,083 \\
\hline
\end{tabular}

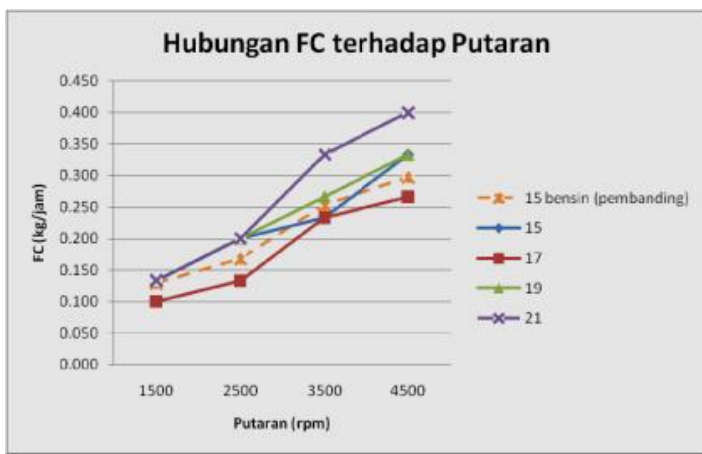

Gambar 3. Grafik hubungan FC terhadap putaran

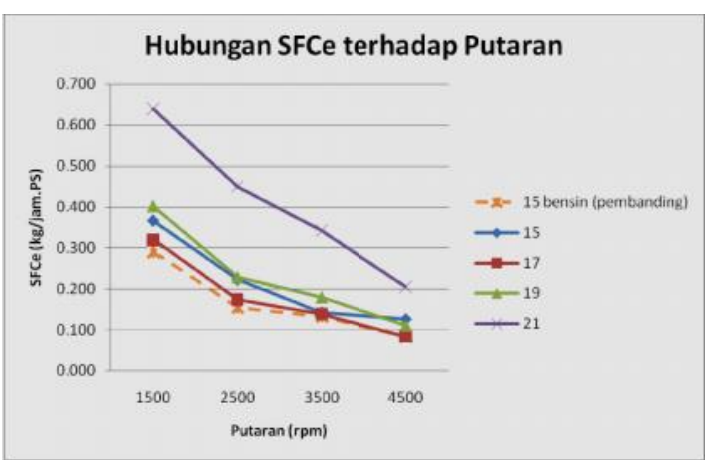

Gambar 4. Grafik hubungan SFCe terhadap putaran.

Dari grafik di atas terlihat semakin tinggi putaran mesin maka SFCe yang dihasilkan semakin rendah. Semakin rendahnya nilai SFCe yang dihasilkan maka tingkat efisiensi penggunaan bahan bakar terhadap daya yang dihasilkan semakin baik.

Dengan penggunaan bahan bakar LPG nilai SFCe terendah dihasilkan pada waktu pengapian $17^{\circ}$ sebelum TMA sebesar $0,084 \mathrm{~kg} / \mathrm{jam} . P S$ dan $\mathrm{SFCe}$ tertinggi dihasilkan pada waktu pengapian $21^{\circ}$ sebelum TMA sebesar $0,640 \mathrm{~kg} / \mathrm{jam} . P S$. Pada putaran $4500 \mathrm{rpm}$ SFCe terendah dihasilkan pada waktu pengapian $17^{\circ}$ sebelum TMA sebesar $0,084 \mathrm{~kg} / \mathrm{jam}$.PS dan tertinggi pada waktu pengapian $21^{\circ}$ sebelum TMA sebesar $0,205 \mathrm{~kg} / \mathrm{jam}$.PS sedangkan dengan penggunaan bahan bakar bensin nilai SFCe yang dihasilkan sebesar 0,083 $\mathrm{kg} / \mathrm{jam} . P S$. 
Pada waktu pengapian $17^{\circ}$ nilai SFCe yang dihasilkan paling rendah dan yang paling tinggi pada waktu pengapian $21^{\circ}$. Hal ini dikarenakan waktu pengapian $17^{\circ}$ sebelum TMA menghasilkan pembakaran yang lebih optimal sehingga tingkat konsumsi bahan bakar terhadap daya yang dihasilkan lebih baik. Berbeda dengan waktu pengapian $21^{\circ}$ sebelum TMA terjadi detonasi. Detonasi ini disebabkan oleh pembakaran terlalu dini yang mengakibatkan puncak ledakan terjadi sebelum torak mencapai $15^{\circ}$ setelah TMA. Hal tersebut terjadi akibat hambatan pada torak saat menuju TMA sehingga sisa daya dari hasil pembakaran hanya sedikit yang bisa diteruskan pada saat langkah usaha sehingga daya yg diteruskan oleh torak lebih kecil dari semestinya, maka dari itu mesin membutuhkan suplai bahan bakar yang lebih banyak untuk mencapai putaran konstan yang diinginkan.

\section{KESIMPULAN}

Dari hasil analisa data dan pembahasan dapat disimpulkan bahwa:

1. Torsi terbesar dengan menggunakan bahan bakar LPG diperoleh pada waktu pengapian $17^{\circ}$ sebelum TMA, sebesar $0,507 \mathrm{kgf} . \mathrm{m}$ pada putaran $4500 \mathrm{rpm}$.

2. Daya efektif terbesar dengan bahan bakar LPG pada waktu pengapian $17^{\circ}$ sebelum TMA, sebesar 3,183 PS pada putaran $4500 \mathrm{rpm}$.

3. Specific fuel consumption effective (SFCe) terendah pada waktu pengapian $17^{\circ}$ sebelum TMA, sebesar 0,084 $\mathrm{kg} / \mathrm{jam} . \mathrm{PS}$ pada putaran $4500 \mathrm{rpm}$.

4. Berdasarkan rata-rata nilai torsi, daya efektif dan SFCe, penggunaan bahan bakar LPG pada waktu pengapian $17^{\circ}$ sebelum TMA masih cenderung lebih rendah jika dibandingkan dengan bahan bakar bensin pada waktu pengapian $15^{\circ}$ sebelum TMA (standar).

\section{SARAN}

Untuk mengembangkan penelitian selanjutnya, maka disarankan motor yang akan digunakan sebagai kendaraan uji sebaiknya menggunakan motor dengan varian terbaru, agar hasil penelitian yang dilakukan relevan dengan perkembangan teknologi motor yang beredar. Dan juga dirasa perlu untuk menggunakan injektor dengan kontrol elektronik (ECM) sehingga efisiensi penggunaan bahan bakar bisa lebih ditingkatkan.

\section{DAFTAR PUSTAKA}

[1] Suryanto, D., 2011, Pengaruh Variasi Sudut Penyalaan Terhadap Daya Engine Toyota K-4 Dengan Bahan Bakar Gas. ISTA. Yogyakarta.

[2] Arismunandar, Wiranto, Prof., Dr., 1988, Motor Bakar Torak, ITB, Bandung.

[3] Mara, I Made \& Nuarsa, I Made, 2001, Diktat Motor Bakar, Jurusan Teknik Mesin, Fakultas Teknik, Universitas Matara, Mataram.

[4] Jama, Jalius Wagino, 2008, Teknik Sepeda Motor Jilid 3 untuk SMK, Direktorat Pembinaan Sekolah Menengah Kejuruan, Direktorat Jenderal Manajemen Pendidikan Dasar dan Menengah, Departemen Pendidikan Nasiona, Jakarta.

[5] Gunadi, 2010, Pengaruh Waktu Pengapian (Ignition Timing) Terhadap Emisi Gas Buang Pada Mobil Dengan Sistem Bahan Bahan Bakar Injeksi (EFI), Fakultas Teknik Universitas Negeri Yogyakarta, Yogyakarta.

[6] Heywood, John B., Prof., Dr., 1988, Internal Combustion Engine Fundamental, Mc Graw-Hill book company Inc, Singapore.

[7] Anonim, 2001, Buku Petunjuk Praktikum Motor Bakar, Jurusan Teknik Mesin, FT-Universitas Brawijaya, Malang. 